\title{
Letter
}

\section{Re; Fibrous Connective Tissue between Müller's Muscle and the Palpebral Conjunctiva as a Reinforcement Structure and a Natural Barrier for the Upper Eyelid}

By

\author{
Hirohiko KAKIZAKI ${ }^{1 *}$, MD, Masahiro ZAKO ${ }^{1}$, MD, PhD, Takashi NAKANO ${ }^{2}$, \\ MD, PhD, Ken ASAMOTO ${ }^{2}$, MD, PhD, Osamu MIYAISHI ${ }^{3}$, MD, PhD, \\ Toshiaki MIYAGAWA ${ }^{4}$, PhD and Masayoshi IWAKI ${ }^{1}, \mathrm{MD}, \mathrm{PhD}$ \\ ${ }^{1}$ Department of Ophthalmology, ${ }^{2}$ Department of Anatomy, Aichi Medical University, Nagakute-cho, Aichi-gun, \\ Aichi-ken, 480-1195, Japan \\ ${ }^{3}$ Department of Clinical Examination, Chubu Rosai Hospital, 1-10-6 Koumei Nagoya-shi, Aichi-ken, 455-8530, Japan \\ ${ }^{4}$ Department of Sports Medicine, Osaka City University Medical School, 3-3-138 Sugimoto, Sumiyoshi-ku, Osaka-shi, \\ Osaka-fu, 558-8585, Japan
}

- Received for Publication, January 14, $2006-$

Our article entitled, "Fibrous Connective Tissue between Müller's Muscle and the Palpebral Conjunctiva as a Reinforcement Structure and a Natural Barrier for the Upper Eyelid" was recently published in Okajimas Folia Anatomica Japonica ${ }^{1)}$. In that article, we stated that the fibrous connective tissue between Müller's muscle and the palpebral conjunctiva continues from the intermuscular transverse ligament (ITL) ${ }^{2,3)}$.

We did not state then the relationship between the fibrous connective tissue and the lamina propria mucosae. Although a lot of vessels are usually included in the lamina propria mucosae ${ }^{4)}$, the present fibrous connective tissue also included a lot of vessels. In this respect, we can say that this fibrous connective tissue is just the lamina propria mucosae; however, since the fibrous connective tissue continues from the ITL $^{1)}$, part of which pulls the upper conjunctival fornix as a supporting structure, we can also say that the fibrous connective tissue acts as the support mechanism for the upper eyelids apart from its natural barrier function as the lamina propria mucosae. In this respect, it is in general different from the lamina propria mucosae.

\section{References}

1) Kakizaki H, Zako M, Nakano T, et al. Fibrous Connective Tissue between Müller's Muscle and the Palpebral Conjunctiva as a Reinforcement Structure and a Natural Barrier for the Upper Eyelid. Okajimas Folia Anat Jpn 2005; 82:7982.

2) Lukas JR, Priglinger S, Denk M, et al. Two fibromuscular transverse ligaments related to the levator palpebrae superioris: Whitnall's ligament and an intermuscular transverse ligament. Anat Rec 1996; 246:415-422.

3) Ettl A, Priglinger S, Kramer J, et al. Functional anatomy of the levator palpebrae superioris muscle and its connective tissue system. Br J Ophthalmol 1996; 80:702-707.

4) Yamada Y. Histology $\left(2^{n d}\right)$. Tokyo, Kanehara \& Co., Ltd. $1991 ; 231$.

* Corresponding author: Hirohiko Kakizaki, Department of Ophthalmology, Aichi Medical University, Nagakute-cho, Aichi-gun, Aichi-ken, 480-1195, Japan. Email: cosme@dl.dion.ne.jp 
